\section{Evaluation of the effect of titanium dioxide and gold nanoparticles surface treatment on the flexural strength of polymethyl methacrylate heat cure denture base resin}

\author{
Rachel Rajan', Vidhya J², Azhagarasan NS², \\ Jayakrishnakumar $\mathbf{S}^{2}$ and Hariharan Ramakrishnan ${ }^{2 *}$ \\ ${ }^{1}$ Prosthodontist, Ragas Dental College and Hospital, Tamilnadu, India \\ ${ }^{2}$ Department of Prosthodontics and Implantology, Ragas Dental College and Hospital, Tamilnadu, \\ India
}

\section{Abstract}

Aim: The purpose of this study was to evaluate the effect of Titanium dioxide and Gold nanoparticles surface treatment on the flexural strength of Polymethyl methacrylate (PMMA) Heat cure denture base resins.

Materials and methods: A total of thirty PMMA Heat cure denture base resin test samples were fabricated of size $65 \times 10 \times 2.5 \mathrm{~mm}$ (rectangular shaped) according to ADA specification no.2. The samples were divided into three groups as Conventional PMMA heat cure denture base resin samples (GROUP I, $n=10 \mathrm{CONTROL),} \mathrm{PMMA} \mathrm{Heat} \mathrm{cure} \mathrm{denture} \mathrm{base} \mathrm{resin} \mathrm{samples} \mathrm{coated} \mathrm{with} \mathrm{Titanium}$ dioxide nanoparticles (GROUP II, $n=10$ ) and PMMA Heat cure denture base resin samples coated with Gold nanoparticles (GROUP III, $n=10$ ). GROUP II and GROUP III PMMA Heat cure denture base resin test samples were coated by Magnetron sputtering. Flexural strength of GROUP I, GROUP II and Group III was evaluated by a three-point bend test using a Universal testing machine and the mean values were obtained.

Results: The Mean flexural strength of GROUP I, GROUP II and GROUP III samples were 114.79 $\mathrm{MPa}, 142.48 \mathrm{MPa}$ and $154.70 \mathrm{MPa}$ respectively. On comparative evaluation of the flexural strength among the three groups GROUP III PMMA Heat cure denture base resin samples exhibited the highest flexural strength followed by GROUP II and least by GROUP I. The statistical analysis by ANOVA had shown that there is significance in flexural strength among the groups tested $\left(p\right.$ - value $\left.=0.000^{*}\right)$.

Conclusion: Within the limitations of the study, PMMA heat cure denture base resin coated with Gold nanoparticles showed the highest flexural strength followed by PMMA Heat cure denture base resin coated with Titanium dioxide nanoparticles. Conventional PMMA Heat cure denture base resin without any surface treatment showed the least flexural strength.

\section{More Information}

*Address for Correspondence: Dr. Hariharan Ramakrishnan, Professor, MDS, Department of Prosthodontics and Implantology, Ragas Dental College and Hospital, 2/102, East Coast Road, Uthandi, Chennai-600119, Tamilnadu, India

\section{Submitted: December 22, 2021}

Approved: January 10, 2022

Published: January 11, 2022

How to cite this article: Rajan R, Vidhya J, Azhagarasan NS, Jayakrishnakumar S, Ramakrishnan H. Evaluation of the effect of titanium dioxide and gold nanoparticles surface treatment on the flexural strength of polymethyl methacrylate heat cure denture base resin. $\mathrm{J}$ Clin Adv Dent. 2022; 6: 001-009.

DOI: 10.29328/journal.jcad.1001025

ORCiD: orcid.org/0000-0003-4466-5744

Copyright: ( 2022 Rajan R, et al. This is an open access article distributed under the Creative Commons Attribution License, which permits unrestricted use, distribution, and reproduction in any medium, provided the original work is properly cited.

Keywords: Polymethyl methacrylate; Denture base; Nanoparticles; Denture; Flexural strength; Gold; Titanium dioxide

Abbreviations: PMMA: Polymethyl Methacrylate; $\mathrm{TiO}_{2}$ : Titanium Dioxide; Au Nps-Gold Nanoparticles

(4) Check for updates

OPEn ACCEss

\section{Introduction}

Oral health is an important aspect for the quality of life especially among elderly and immune compromised patients. There are a number of reasons associated with edentulism, for instance, age, disease, accident, smoking or alcoholic history [1,2]. The replacement of missing teeth by an artificial substitute, such as a denture is essential for the health and well-being of many individuals [3]. Various materials have been employed for the fabrication of dentures since the $20^{\text {th }}$ century such as bakelite, stainless steel, vinyl resin, nylon, and polystyrene [4]. However, the disadvantages of these materials like absence of chemical bonding, poor esthetics due to its metallic colour, difficulty in manipulation, hardness, being prone to discolouration, inadequate mechanical properties restrict their further application in the field of denture base industry [5].

There is continuous research for a material that has good uniformity, biocompatibility, low density, cost effectiveness, relatively lower toxicity, ease of processing and repair techniques. Acrylic resin stood as a gold standard material 
of choice, among all the others and became the most popular non-metallic denture base material [4]. The ideal properties of Polymethyl methacrylate (PMMA) are elastic modulus, flexural strength, fracture toughness, impact strength and knoop hardness, coefficient of thermal expansion, curing shrinkage, sorption, solubility and colour [5]. However, the PMMA denture base is susceptible to microbial colonization in the oral environment. The common drawbacks of PMMA are dimensional changes, susceptibility to fracture, residual monomers and increased risk of denture associated infections [6].

Denture base materials should possess adequate flexural and surface properties for a successful denture and patient satisfaction. Dentures are subjected to flexural stress during mastication because of its uneven alveolar ridges due to the gradual irregular pattern of bone resorption. Therefore, high flexural strength of denture base material is needed to avoid denture fracture under flexural loading [7]. Intraoral forces can induce a fatigue process in the denture base, giving rise to small flexural stresses that may result in formation of small cracks. Because dentures are usually broken when they are loaded beyond their maximum capacity, the propagation of these cracks over time will eventually cause denture fractures [5]. The denture failure in clinical service is a major concern resulting in several attempts to improve both the flexural and impact strength of denture base resins [8]. Studies have revealed that $68 \%$ of acrylic dentures has been fractured within few years of delivery, while $39 \%$ of dentures require repair within 3 years of insertion.

Atypical manifestation of fatigue failure in a maxillary denture is midline fracture, usually starting at the labial notch area or at the anterior portion of the palatal area of the denture base. The flexural strength test (also known as transverse or three-point bending test) is considered a reflection of the resistance and stiffness of the tested material, encompassing the material's tensile, shear and compressive strengths [5].

The mechanical properties are equally important as that of the antimicrobial properties, since, the PMMA in the dental prosthesis will be subjected to high-pressure during mastication $[9,10]$. Efforts have been made to improve the mechanical properties of PMMA denture base material. These include modifying composition of the material utilizing different polymerization techniques or adding reinforcement materials. In previous studies improvement of tensile and bending strengths have been attempted using cross linking monomers but no marked effects have been achieve [11].

Different techniques including a rubber phase, metal wires, metal oxides, fibres and fillers were used to improve their mechanical properties. Developments in the field of nanotechnology, nanoparticles, nanotubes and nanofibers were recently used to reinforce acrylic resins [12]. The concept of "Nanomaterial" formed in the early 1980s, referring to zerodimensional, one-dimensional, two-dimensional, and threedimensional materials with a size of less than $100 \mathrm{~nm}$ [7]. The concept of nanotechnology was first introduced in 1959 by Feynman. Since then, nanotechnology has been widely used in many applications, including medical sciences. Nanoparticles (Nps) are characterized by smaller size, larger specific surface area and strong interfacial interaction with organic polymers. The surface of the material is in nanometre dimension which leads to its unique properties [12].

Recently various nanomaterials have been used in PMMA reinforcement like different types of metals such as Aluminium oxide, Zirconium oxide, Titanium dioxide, Silver nanoparticle, Nano-Gold, Platinum and Palladium, fibres such as Glass fibres, Polyamide fibres, Polyethylene, Polypropylene fibres and natural fibres, Hydroxyapatite fillers, Silicon dioxide, Mica and Nano fillers, Nanotube, Nano-clay, Nano-carbon and Nano-diamond [13].

Nidal W Elshereksi, et al. suggested that Titanium as nanofillers are used as an additive in dental materials and to enhance the mechanical properties of dental resins [14]. Al-Harbi, et al. in his study evaluated the increased flexural strength, decreased impact strength and surface roughness by the addition of nano-diamond [15].

Titanium dioxide $\left(\mathrm{TiO}_{2}\right)$ nanoparticle is one of the most commonly used nanomaterials that have been investigated due to its unique properties. The Titanium dioxide nanoparticles were used to increase the mechanical properties of PMMA. Titanium dioxide $\left(\mathrm{TiO}_{2}\right)$ nanoparticles have multiple effects, benefits, and applications. In addition, a significant increase in impact strength, a significant decrease in water sorption and solubility were found upon addition of $\mathrm{TiO}_{2}$ nanoparticles to Polymethyl methacrylate (PMMA). Titanium dioxide $\left(\mathrm{TiO}_{2}\right)$ film/particles can inactivate $C$. albicans after 30 to 90 minutes of UV light (315- $400 \mathrm{~nm}$ ) exposure. An additional benefit of Titanium dioxide $\left(\mathrm{TiO}_{2}\right)$ nanoparticle is its super hydrophilic behavior, commonly known as the "water sheathing effect." These demonstrated better mechanical properties, antimicrobial activity, cleanability, and biocompatibility on coating $\mathrm{TiO}_{2}[16]$.

Gold nanoparticles (Au Nps) are also a good choice for nanofillers in PMMA because they have desirable properties such as stability, non-toxicity, uniform particle size and antimicrobial properties $[9,10]$. Gold is known for its excellent biocompatibility and corrosion resistance. Nano Gold ( $\mathrm{Au}$ ) recently was suggested to improve the properties of PMMA denture base. The studies available on the effect of adding Nano Gold to PMMA are still limited at the present time. It has been observed that incorporating Gold nanoparticles considerably improved the flexural strength and thermal conductivity to almost double the value of conventional PMMA, which could lead to more patient satisfaction [13]. 
To achieve good dispersion of nanoparticles within polymers, different methods of nanoparticles addition were suggested. It is either added to the acrylic powder where the required percentages were weighed and mixed with the powder. Or it can be added to the liquid monomer. In some studies nanoparticles have been added by spray or sol-gel method which did not influence the mechanical and surface properties of PMMA. Few studies have investigated the coating of thin film of PMMA to improve the mechanical properties [13]. Darwish, et al. concluded that the coating of novel Titanium dioxide nanoparticle $\left(\mathrm{TiO}_{2}\right)$ thin film improves the surface smoothness, mechanical properties, improved wettability and resistance to microbial adherence [16].

Out of all the methods used for coating of Nano thin film deposition, low temperature deposition method is found to be more effective and stable such as atomic layer deposition (ALD), chemical vapor deposition (CVD), pulsed laser deposition (PLD) and a physical vapor deposition (PVD). These methods exhibit a few disadvantages such as a long duration of optimization of the vacuum chamber and cost factor.

Sputter deposition is a well-known technique commonly used for thin film deposition by sputtering [17]. Magnetron sputtering (MS) is one of the most widely used plasma surface engineering methods (PSE) in the field of nanoscience. It can operate by keeping a relatively low temperature and excellent adhesion of the coating nanoparticle to the substrate, by using low power during the process of a coating synthesis [18].

Sputtering is a deposition process based on the ejection of atoms, molecules, or molecular fragments from a target that is bombarded by energetic particles and subsequent condensation of emitted particles on adjacent surfaces [17]. The general sputtering method can be used to prepare a variety of materials such as metals, semiconductors, insulators and also has the advantages of simple equipment, easy control, large coating area and strong adhesion. Since, its development from1970's magnetron sputtering method achieves high speed, low temperature and low damage [18].

Several studies have been investigated on the incorporation and coating effect of Titanium dioxide nanoparticles and only fewer studies have investigated addition of Gold nanoparticles on the properties of PMMA. There are no studies which compared the effect of flexural strength on both Titanium dioxide nanoparticles and Gold nanoparticles coating on (PMMA) Polymethyl methacrylate heat cure denture base resins.

In view of the above, the present in vitro study was conducted to compare and evaluate the effect of Titanium dioxide and Gold nanoparticles surface treatment on the flexural strength of Polymethyl methacrylate (PMMA) heat cure denture base.

\section{Materials and methods}

\section{Materials used in the study}

Plaster of Paris (Dental Grade - Ramaraju Mills Ltd, India), mold separating medium (cold mold seal) (DPI, India), polyethylene sheets (DPI, India), PMMA heat cure denture base resin (Trevalon, Dentsply, Pvt Ltd. India) (Figure 1).

The methodology adopted in the present study is described under the following sections:

Fabrication of PMMA heat cure denture base resin samples: Fabrication of custom made Stainless steel metal die. Flasking of the stainless steel metal die for test samples. Acrylization of PMMA heat cure denture base resin samples. Finishing and polishing of the test samples. Surface coating of Titanium dioxide nanoparticles $(n=10)$ and Gold nanoparticles $(n=10)$ on PMMA heat cure denture base resin samples by magnetron sputtering technique. Grouping of the test samples. Sample storage. Evaluation of flexural strength of test samples. Data tabulation and analysis

i. Fabrication of PMMA heat cure denture base resin samples: Fabrication of custom made stainless steel metal die: Thirty custom made rectangular stainless steel metal dies were milled of size $65 \times 10 \times 2.5 \mathrm{~mm}$ (Figure 2) according to ADA specification no.12 [34].

ii. Flasking of the stainless steel metal die for test samples: accurately weighed dental plaster was mixed in water with a water powder ratio of 0.45 using a vacuum mixer for 25 seconds and mix was poured in the lid of a dental flask and the customized stainless steel metal dies (Figure 3) were invested. The plaster was allowed to set for 30 minutes after which cold mold seal was applied using a camel hair brush and the second pour was done, by mixing the plaster in water as already mentioned. The plaster was allowed to set for an hour, and the parts of the flask were separated. The stainless steel metal dies were retrieved to create the mold space for the acrylic specimen.

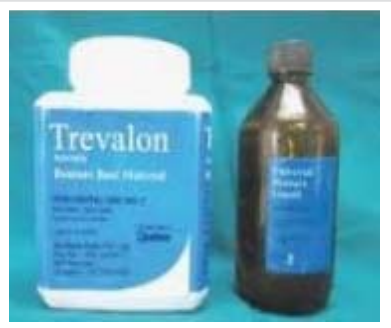

Figure 1: Trevalon.

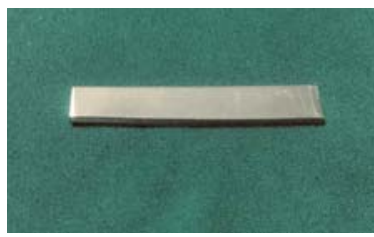

Figure 2: Metal dies. 
iii. Acrylization of PMMA Heat cure denture base resin Samples: (Figure 4) the packing procedure of Heat cure denture acrylic resin was adopted. Cold mold seal (DPI, India) was applied onto the mold cavity, preventing pooling of the solution and the solution was permitted to dry. PMMA Heat cure denture base resin was mixed in the polymer to monomer ratio of $3: 1$ by volume in a porcelain mixing jar and was allowed to reach the dough like consistency. The resin was then removed from the mixing jar and placed into the mold space. A polyethylene sheet (DPI, India) was placed over the resin and the flask was reassembled. The flask assembly was then placed into a specially designed press and pressure (confident dental equipment limited, Bangalore, India) was applied incrementally, until the denture flask was firmly closed. The flask portions were then separated and the polyethylene packing sheet was removed and flash was eliminated. Repeated trial closures were done placing polyethylene sheets until no flash was observed, after which definitive closure of the flask was done without polyethylene sheet. The flask was maintained under pressure until bench curing was complete. The flask was then placed in acrylizer (C-73, confident dental equipment ltd, Bangalore, India) for curing procedure in a constant temperature water bath maintained at 74 degree Celsius for 8 hours. Following the completion of polymerization cycle, the flasks were cooled slowly to room temperature.

iv. Finishing and polishing of the test samples: The retrieved acrylic resin samples from the dental flask were then subjected to finishing and polishing procedures. Thus a total of thirty PMMA Heat cure denture base resin samples were fabricated.

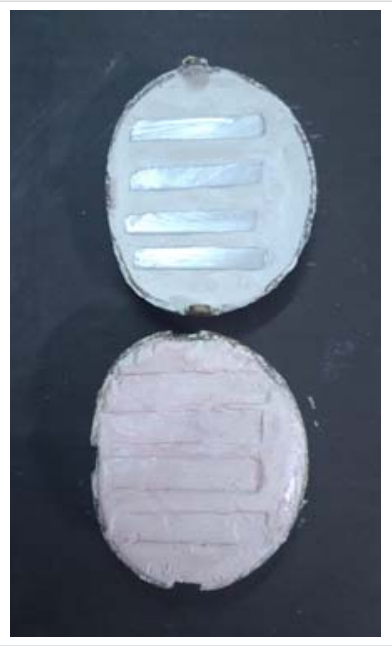

Figure 3: Mold space for acrylic specimens.

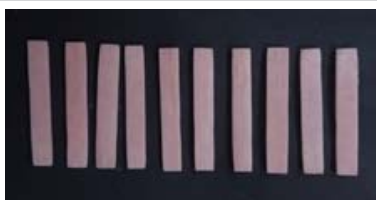

Figure 4: PMMA heat cure denture base resin samples. v. Surface Coating of Titanium dioxide nanoparticles $(n=10)$ and Gold nanoparticles $(n=10)$ on PMMA Heat cure denture base resin samples by magnetron sputtering technique. Magnetron sputtering (SC 7620, UK) (Figure 5) is a deposition technology involving a gaseous plasma which is generated and confined to a space containing the material to be deposited the 'target' (Figure 6) $[17,18]$. The surface of the target is eroded by high energy ions within the plasma, and the liberated atoms travel through the vacuum environment and deposit onto the substrate to form a thin film. During the sputtering deposition process, a chamber is first evacuated to high vacuum to minimize the partial pressures of all background gases and potential contaminants. After base pressure has been reached, sputtering gas which comprises the plasma is flowed into the chamber and the total pressure is regulated using a pressure control system. The sputtering device consists of a $50 \mathrm{~L}$ stainless steel vessel (SC7620) (Figure 7). A base pressure of less than $10^{3} \mathrm{~Pa}$ was obtained with a turbo molecular pump unit. Titanium dioxide target of $65 \mathrm{~mm}$-diameter and $3 \mathrm{~mm}$-thick and Gold Target of $60 \mathrm{~mm}$ - diameter and $2.5 \mathrm{~mm}$ - thick was sputtered using a plasma current power supply. PMMA substrates in the form of a $2.5 \mathrm{~mm}$ thick rectangular sample were distanced from the magnetron target perpendicularly at $5 \mathrm{~cm}$. Out of the thirty test samples, ten test samples were selected for coating Titanium dioxide nanoparticles and the other ten test samples were selected for coating Gold nanoparticles. The coating of a thin film of Titanium dioxide nanoparticles and Gold nanoparticles on PMMA substrate was executed by magnetron sputtering method. The samples were coated with approximately $20 \mathrm{~nm}$ thick Titanium dioxide $\left(\mathrm{TiO}_{2)}\right.$ and Gold

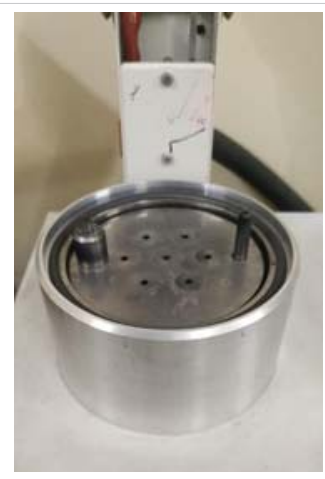

Figure 5: Magnetron sputtering device vessel.

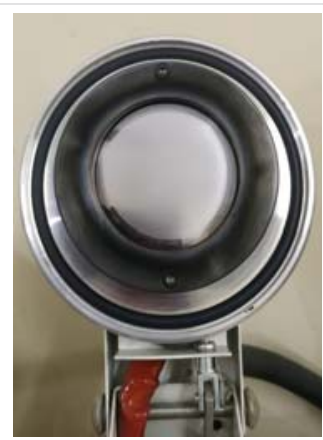

Figure 6: Sputtering target. 
nanoparticles. Argon gas (Figure 8) was regulated at constant flow rate being monitored in real time by the pressure control system. Grouping of the test samples. The test samples were divided into three groups: GROUP I: Conventional PMMA Heat cure denture base resin samples ( $n=10$ Control), GROUP II: PMMA Heat cure denture base resin samples coated with Titanium dioxide nanoparticles $(n=10)$ (Figure 9), GROUP III: PMMA Heat cure denture base resin samples coated with Gold nanoparticles $(n=10)$ (Figure 10).

vi. Sample storage. The samples for testing the flexural strength were immersed in the water bath at $37^{\circ} \mathrm{C}$ for 1 week to simulate the in vivo oral environment.

vii. Evaluation of flexural strength of test samples: The flexural strength of all the test samples were evaluated with the use of three-point bend test in Universal testing machine. The samples were subjected to three-point bend test in universal testing machine (Figure 8) at crosshead speed of $5 \mathrm{~mm} / \mathrm{min}$

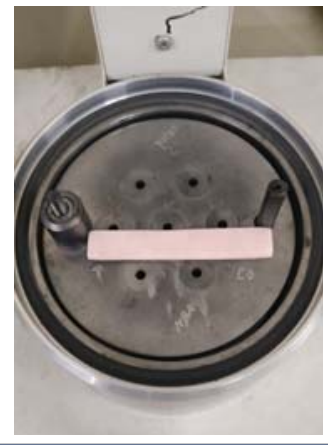

Figure 7: Sample placed in sputtering device.

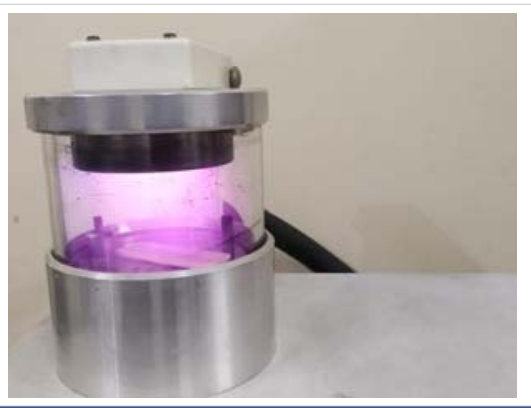

Figure 8: Magnetron sputtering argon chamber.

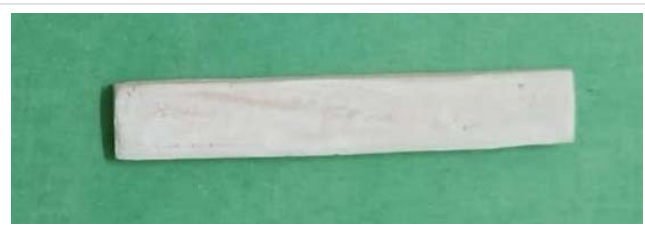

Figure 9: Titanium dioxide nanoparticles coating.

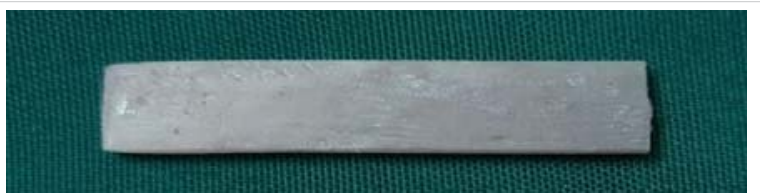

Figure 10: Gold nanoparticles coating and the values were recorded using computer software. The flexural testing device consisted of a central loading plunger and two supports. The distance between the supports was $50 \mathrm{~mm}$ (represents the space between the maxillary molars in a complete denture). The load was applied perpendicular to the centre of the specimen until fracture occurred. Flexural strength was calculated using the equation: $\mathrm{FS}=3 \mathrm{FL} / 2 \mathrm{bd} 2$ Where, FS - flexural strength in (MPa), F - Load or force at fracture in $(\mathrm{N}) \mathrm{L}$ - Span length of specimen between two supports $(50 \mathrm{~mm}), \mathrm{b}$ - Width, $\mathrm{d}$ is the thickness [19].

viii. Data tabulation and analysis: The basic data obtained were tabulated using Microsoft Excel 2013 (Microsoft, USA.) and the Mean and Standard deviation were calculated. The data were subjected to statistical analysis for test of significance using SPSS Software version 21 (SPSS Software Corp., Munich, Germany). Flexural strength was analysed both within the groups and between the test groups using One-way ANOVA, Posthoc tukey HSD test and $p$ - value of 0.05 was considered statistically significant.

\section{Results}

The basic data (Table 1) for evaluation of flexural strength of GROUP I, GROUP II and GROUP III of PMMA Heat cure denture base resin samples and their Mean value and statistical analysis was done using One-way ANOVA and Posthoc tukey HSD test. The maximum flexural strength for PMMA Heat cure denture base resin samples is $126.78 \mathrm{MPa}$. The minimum flexural strength for PMMA Heat cure denture base resin samples is $90.91 \mathrm{MPa}$. The Mean value of flexural strength of PMMA Heat cure denture base resin samples is 114.79 MPa. The maximum flexural strength for PMMA Heat cure denture base resin samples Coated with Titanium dioxide nanoparticles is $176.34 \mathrm{MPa}$. The minimum flexural strength for PMMA Heat cure denture base resin samples coated with Titanium dioxide nanoparticles is $121.23 \mathrm{MPa}$. The Mean value of flexural strength of PMMA Heat cure denture base resin samples coated with Titanium dioxide nanoparticles is $142.48 \mathrm{MPa}$. The maximum flexural strength for PMMA Heat cure denture base resin samples Coated with Gold nanoparticles is $166.73 \mathrm{MPa}$. The minimum flexural strength for PMMA Heat cure denture base resin samples coated with Gold nanoparticles is $136.32 \mathrm{MPa}$. The Mean value of flexural strength of PMMA Heat cure denture base resin samples coated with Gold nanoparticles is $154.70 \mathrm{MPa}$.

Comparative evaluation of the mean flexural strength of GROUP I, GROUP II and GROUP III of PMMA Heat cure denture base resin samples using One-way ANOVA test is given in (Table 2). Multiple comparisons of the mean flexural strength of GROUP I, GROUP II and GROUP III PMMA Heat cure denture base resin samples using Posthoc tukey HSD test is given in (Table 3).

\section{Discussion}

The major drawback of PMMA is its inadequate mechanical 
Table 1: Data of flexural strengths of the three groups.

\begin{tabular}{|c|c|c|c|}
\hline Sample Number & $\begin{array}{c}\text { Group I } \\
\text { (Flexural Strength GROUP } 1 \text { (MPa) }\end{array}$ & $\begin{array}{l}\text { Group II } \\
\text { (Flexural Strength GROUP } 11 \text { (MPa) }\end{array}$ & $\begin{array}{c}\text { Group III } \\
\text { (Flexural Strength GROUP } 111(\mathrm{MPa})\end{array}$ \\
\hline 1. & 108.52 & 155.51 & 165.42 \\
\hline 2. & 90.91 & 136.43 & 151.52 \\
\hline 3. & 122.08 & 136.43 & 136.32 \\
\hline 4. & 108.52 & 136.43 & 149.21 \\
\hline 5. & 94.61 & 121.23 & 166.73 \\
\hline 6. & 121.21 & 131.21 & 136.47 \\
\hline 7. & 126.78 & 176.34 & 151.52 \\
\hline 8. & 122.08 & 126.78 & 162.78 \\
\hline 9. & 126.78 & 155.23 & 162.78 \\
\hline 10. & 126.47 & 149.23 & 164.34 \\
\hline Mean & 114.79 & 142.48 & 154.70 \\
\hline
\end{tabular}

Inference: The maximum flexural strength for PMMA Heat Cure Denture Base Resin samples (GROUP 1) is 126.78MPa. The minimum flexural strength for PMMA Heat Cure Denture Base Resin samples is $90.91 \mathrm{MPa}$. The Mean value of flexural strength of PMMA Heat Cure Denture Base Resin samples is $114.79 \mathrm{MPa}$.

The maximum flexural strength for PMMA Heat Cure Denture Base Resin samples (GROUP II) Coated with Titanium dioxide nanoparticles is 176.34 MPa. The minimum flexural strength for PMMA Heat Cure Denture Base Resin samples coated with Titanium dioxide nanoparticles is $121.23 \mathrm{MPa}$. The Mean value of flexural strength of PMMA Heat Cure Denture Base Resin samples coated with Titanium dioxide nanoparticles is $142.48 \mathrm{MPa}$.

The maximum flexural strength for PMMA Heat Cure Denture Base Resin samples (GROUP III) Coated with Gold nanoparticles is 166.73 MPa. The minimum flexural strength for PMMA Heat Cure Denture Base Resin samples coated with Gold nanoparticles is 136.32 MPa. The Mean value of flexural strength of PMMA Heat Cure Denture Base Resin samples coated with Gold nanoparticles is $154.70 \mathrm{MPa}$.

Table 2: Comparative evaluation of the Mean Flexural strength of GROUP I, GROUP II and GROUP III PMMA Heat Cure Denture Base Resin samples using Oneway ANOVA test.

\begin{tabular}{|c|c|c|c|}
\hline GROUPS & N & Mean & Std. deviation \\
\hline GROUP I & 10 & 114.79 & 13.4476 \\
\hline GROUP II & 10 & 142.48 & 16.5303 \\
\hline GROUP III & 10 & 154.70 & 11.564 \\
\hline
\end{tabular}

If $p$ - value is .000 to .010 then denoted by** it implies significant at $1 \%$ level (highly significant)

Inference: On comparative evaluation of the flexural strength among the three groups tested, GROUP III exhibited the highest flexural strength followed by GROUP II and least by GROUP I. The statistical analysis by Oneway ANOVA had shown that there is significance in flexural strength among the groups tested $\left(p-\right.$ value $\left.=0.000^{*}\right)$.

Table 3: Multiple comparisons of the Mean flexural strength of GROUP I, GROUP II and GROUP III PMMA Heat Cure Denture Base Resin samples using Post - Hoc Tukey HSD test.

\begin{tabular}{|c|c|c|}
\hline Group (I) & Group (J) & Mean differences (I-J) \\
\hline \multirow{2}{*}{ GROUP I } & GROUP II & $27.68600^{*}$ \\
\hline \multirow{2}{*}{ GROUP II } & GROUP III & $-39.91300^{*}$ \\
\hline \multirow{2}{*}{ GROUP III } & GROUP I & 27.68600 \\
\hline & GROUP III & -12.22700 \\
\hline
\end{tabular}

Inference: On statistical analysis using Post - Hoc Tukey HSD test for multiple comparisons, the Mean flexural strength exhibited with Group II test samples is higher than that of Group I test samples and the difference was found to be statistically highly significant $\left(p<0.01^{* \star}\right)$. The Mean flexural strength exhibited with Group III test samples is higher than that of Group I test samples and the difference was found to be statistically highly significant $\left(p<0.01^{* *}\right)$. The Mean flexural strength exhibited with Group III test samples is higher than that of Group II test samples and the difference was found to be statistically not significant $\left(p>0.05^{*}\right)$.

and physical properties such as low flexural strength, low impact strength and low surface hardness that leads to reduced clinical performance of the denture $[19,20]$.

Denture base materials should possess adequate flexural and surface properties for a successful denture and patient satisfaction [21]. ISO 20795-1 (2013) International standards have established $65 \mathrm{MPa}$ as the minimum flexural strength required for all acrylic resins used for denture bases $[9,10]$. Dentures are subjected to flexural stress during mastication. Therefore, a high flexural strength of denture base material is needed to avoid denture fracture under flexural loading [7]. Smith has suggested that repeated flexing from chewing fatigues denture with use. Intraoral forces can induce a fatigue process in the denture's base, giving rise to small flexural stresses that may result in formation of small cracks, when they are loaded beyond their maximum capacity, the propagation of these cracks over time will eventually cause fractures $[27,28]$.

In the past, different reinforcing agents such as chemical modifiers, rubbers, metals, macro fibres, and fillers have been employed to improve mechanical properties of denture base resins [35]. In previous studies improvement of tensile and bending strengths has been attempted using crosslinking monomers but no marked effects have been achieved [11]. Another study researched to increase its mechanical properties by the incorporation of a rubber phase in the bead polymer but it is expensive [20].

According to Aoyagi, et al. aramid fibres reinforced on the mechanical properties showed some disadvantages such as poor esthetics and difficulties in polishing. In the case of 
polyethylene fibres the surface treatment to improve adhesion between fibres and denture base polymer is complicated [11].

Different mechanisms have been presented by Abdulrazzaq Naj, et al. for the reinforcing effect of nano fibres /tubes [22]. A larger surface area can provide a larger area for load transfer and facilitate toughening mechanisms such as fibre/tube bridging and fibre /tube pull-out. A study by Karci, et al. showed significant increase in the flexural strength after addition of different nanoparticles such as Aluminium oxide, Silicon dioxide and Titanium dioxide [32]. Titanium dioxide $\left(\mathrm{TiO}_{2}\right)$ nanoparticle is one of the most commonly used nanomaterial's that was found to have multiple effects, benefits and applications. Previous studies have found that adding Titanium dioxide nanoparticles $\left(\mathrm{TiO}_{2}\right)$ to PMMA have improved the surface mechanical properties, surface wettability and decreased microbial adhesion $[16,36]$.

Another study researched the interaction between PMMA and $\mathrm{TiO}_{2}$ nanoparticle and found they interact chemically and physically [23]. Some authors reported that the addition of Titanium dioxide $\left(\mathrm{TiO}_{2}\right)$ nanoparticles to PMMA will lead to a significant decrease in the porosity of the denture resin $[24,33,34]$.

Recently, Gold nanoparticles (Au Nps) has also been a good choice for nano fillers in PMMA because they have desirable properties, such as stability, non-toxicity, uniform particle size and antimicrobial properties biocompatibility and corrosion resistance $[9,10]$. Morsy Mohammed observed that incorporating Gold nanoparticles (Au Nps) considerably improved the flexural strength and thermal conductivity to almost double the value of pure PMMA, which could lead to more patient satisfaction [25]. However, studies available on the effect of adding Nano-Gold to PMMA are still limited at the present time. Also studies comparing the coating of Titanium dioxide and Gold nanoparticles on PMMA are lacking in literature [13].

To achieve good dispersion of nanoparticles within polymers, different methods of nanoparticles addition were suggested. It is either added to the acrylic powder where the required percentages were weighed and mixed with the powder. Or it can be added to the liquid monomer [31]. In some studies nanoparticles have been added by spray or sol-gel method which did not influence the mechanical and surface properties of PMMA. Few studies have investigated the coating of thin film of PMMA to improve the mechanical properties. This method of coating improves the mechanical properties of PMMA, quality of the surface of the resin, improves wettability, reduces adhesion of food bolus and suppresses the microbial adhesion [13].

Plasma surface engineering (PSE) methods have been recommended for the deposition of Titanium dioxide and metallic layers on PMMA. Out of all PSE methods, low temperature deposition method is found to be more effective and stable such as atomic layer deposition (ALD), chemical vapor deposition (CVD), pulsed laser deposition (PLD) and a physical vapour deposition (PVD). These methods exhibits a few drawbacks such as a long duration of optimization of the vacuum chamber and cost factor [18].

Magnetron sputtering is a well-known sputtering technique commonly used for thin compact film deposition [17]. Magnetron sputtering (MS) is a plasma surface engineering methods (PSE) in the field of nanoscience. It can operate by keeping a relatively low temperature and excellent adhesion of the coating nanoparticle to the substrate during the process of coating synthesis. The sputtering method has the advantages of simple equipment, easy control, large coating area, and strong adhesion [18].

All the steps discussed in the methodology for the test sample preparation were adopted from the methodology described in the previous studies. All the procedures were performed by a single operator in order to avoid errors by multiple operators.

The results of the present study revealed the mean value of flexural strength of PMMA Heat cure denture base resin samples (GROUP I) is $114.79 \mathrm{MPa}$. The mean value of flexural strength of PMMA Heat cure denture base resin samples coated with Titanium dioxide nanoparticles (GROUP II) is 142.48 MPa. The mean value of flexural strength of PMMA Heat cure denture base resin samples coated with Gold nanoparticles (GROUP III) is $154.70 \mathrm{MPa}$. On comparative evaluation of the flexural strength among the three groups tested, GROUP III exhibited the highest flexural strength followed by GROUP II and least by GROUP I. The statistical analysis by Oneway ANOVA had shown that there is significance in flexural strength among the groups tested ( $p$ value $=0.000 *$ ). GROUP III showed a color change perceptible at a glance. The results obtained in the present study are in accordance with the study conducted by Morsy Mohamed, polymer thin film thickness of a size ranging from $10 \mathrm{~nm}$ to about $40 \mathrm{~nm}$ showed an increase in the flexural strength after addition of Gold nanoparticles on PMMA resin [25]. In this present study the coating of thin film thickness was determined using the formula $d=($ KVIT $) \AA$ d- Coating thickness, K- 0.17 (with Argon) constant, I- Plasma current $\left(1 \mathrm{~mA}=10^{-3}\right) \mathrm{A}, \mathrm{V}$ - voltage applied $\left(1 \mathrm{kv}=10^{3} \mathrm{~A}\right)$, Tsputtering time $(120 \mathrm{sec})$ and resulted with thickness' of 20 nm approximately.

$$
\mathrm{d}=(\mathrm{KVIT}) \AA=0.17 * 1 * 10^{3 *} 1 * 10^{-3 *} 120=20.4 \mathrm{~nm}
$$

However, Tijana, et al. in his study concluded that addition of Gold nanoparticles led to a decrease in the flexural strength of PMMA resin [9]. This may be due to the lesser concentration of nanoparticles added to PMMA. At the same time there was an increase in the thermal conductivity and hardness [10].

Oyar, et al. in his study concluded that addition of Gold nanoparticles improved the flexural strength of PMMA [26]. 
Aoyagi, et al. in his study investigated the colour changes after addition of noble metal clusters Gold, Platinum and Palladium and noted significantly higher colour differences with the amount of addition and thermal treatment temperatures. In the present study perceptible colour change noted on Gold coated samples might be due to the thickness of the Gold coating on PMMA [12].

The results in the present study is in line with Hashem, et al's study in which he concluded that addition of Titanium dioxide nanoparticle exhibited a linear increase in flexural strength [29]. They also suggested that reinforced PMMA could offer superior chemical and mechanical properties making it a better option for dentures than pure PMMA resin material. Rashahmadi, et al. also found that addition of Titanium dioxide nanoparticle improved the flexural strength of PMMA resin [6]. Darwish, et al. in his study coated a thin layer of Titanium dioxide on PMMA and noticed a slight increase in the flexural strength of PMMA which was not statistically significant [16].

Sodagar, et al. investigated the effect of adding $0.5 \%$ and $1 \%$ Titanium dioxide nanoparticle into PMMA and reported a decrease in flexural strength [30]. PMMA containing 0.5wt\% showed the lowest values. It was concluded that there is an inverse relation between the concentration of the filler and the flexural strength of reinforced PMMA [31]. The findings in the present study reveals that, Polymethyl methacrylate (PMMA) Heat cure denture base resins samples coated with Gold nanoparticles exhibited the maximum flexural strength followed by Polymethyl methacrylate (PMMA) Heat cure denture base resin samples coated with Titanium dioxide nanoparticles. Conventional Polymethyl methacrylate (PMMA) Heat cure denture base resin showed the least flexural strength. Thus, the null hypothesis of this study is invalidated, because the present study had revealed that there was statistically highly significant difference in the flexural strength of conventional Polymethyl methacrylate (PMMA) Heat cure denture base resins, PMMA Heat cure denture base resins coated with Titanium dioxide nanoparticles and PMMA Heat cure denture base resins coated with Gold nanoparticles.

The present study had some limitations. Other properties like wear resistance, surface roughness, impact strength, color stability and antimicrobial efficacy were not evaluated in the present study. The influence of differing thickness of Titanium dioxide $\left(\mathrm{TiO}_{2}\right)$ and Gold (Au Nps) nanoparticles on the property tested in this study is unknown. Long term clinical studies are further required to assess the durability of dentures.

\section{Conclusions}

1. PMMA heat cure denture base resin coated with Gold nanoparticles showed the highest flexural strength.

2. PMMA Heat cure denture base resin coated with Titanium dioxide nanoparticles showed second-best flexural strength.
3. Conventional PMMA heat cure denture base resin without any coating or surface treatment showed the least flexural strength.

\section{Clinical significance}

Heat cure Polymethyl methacrylate impregnated with Gold nanoparticles can be used in clinical situations as a denture base material for restoration of edentulous maxilla and mandible.

\section{References}

1. Enberg N, Wolf J, Ainamo A, Alho H, Heinälä $P$, Lenander-Lumikari M Dental diseases and loss of teeth in a group of Finnish alcoholics: a radiological study. Acta Odontol Scand. 2001; 59: 341-347.

PubMed: https://pubmed.ncbi.nlm.nih.gov/11831482/

2. Thorstensson $\mathrm{H}$, Johansson $\mathrm{B}$. Why do some people lose teeth across their lifespan whereas others retain a functional dentition into very old age? Gerodontology. 2010; 27: 19-25.

PubMed: https://pubmed.ncbi.nlm.nih.gov/19545321/

3. Kanazawa M, Inokoshi M, MinakuchiS, Ohbayashi N. Trial of a CAD/CAM system for fabricating complete dentures. Dent Mater J. 2011; 30: 93-96. PubMed: https://pubmed.ncbi.nlm.nih.gov/21282882/

4. Khindria K, Mittal S, Sukhija U. Evolution of denture base materials. J Indian Prosthodont Soc. 2009; 9: 64-69.

5. Zafar MS. Prosthodontic Applications of Polymethyl Methacrylate (PMMA): An Update. Polymers. 2020; 12: 2299. PubMed: https://pubmed.ncbi.nlm.nih.gov/33049984/

6. Gad M, Abualsaud R. Behavior of PMMA Denture Base Materials Containing Titanium Dioxide Nanoparticles: A Literature Review. Int J Biomater. 2019; 2019: 6190610.

PubMed: https://pubmed.ncbi.nlm.nih.gov/30792739/

7. Gad MM, Fouda SM, ArRejaie AS, Al-Thobity AM. Comparative Effect of Different Polymerization Techniques on the Flexural and Surface Properties of Acrylic Denture Bases. J Prosthodont. 2019; 28: 458-465. PubMed: https://pubmed.ncbi.nlm.nih.gov/28543925/

8. Cevik P, Yildirim-Bicer AZ. The Effect of Silica and Prepolymer Nanoparticles on the Mechanical Properties of Denture Base Acrylic Resin. J Prosthodont. 2018; 27: 763-770.

PubMed: https://pubmed.ncbi.nlm.nih.gov/27898997/

9. Adamović T, Veselinović V, Trtic N, Hadži-Mihailović M, Atlagić G, et al Mechanical properties of new denture base material modified with Gold nanoparticles. J Prosthodont Res. 2021; 65: 155-161. PubMed: https://pubmed.ncbi.nlm.nih.gov/32938880/

10. Tijana $A$, Valentina $V$, Nataša $T$, et al. Mechanical properties of new denture base material modified with Gold nanoparticles. J Prosthodont Res. 2020; 65:155-161.

PubMed: https://pubmed.ncbi.nlm.nih.gov/32938880/

11. Aoyagi Y, Miyasaka T, Ando N. Application of noble metal cluster to PMMA resin And influence on mechanical properties and color. Dent Mater J. 2015; 34: 781-788.

PubMed: https://pubmed.ncbi.nlm.nih.gov/26632226/

12. Takahashi Y, Yoshida K, Shimizu H. Fracture resistance of maxillary complete dentures subjected to long-term water immersion. Gerodontology. 2012; 29: e1086-1091.

PubMed: https://pubmed.ncbi.nIm.nih.gov/22260149/

13. Gad MM, Fouda SM, Al-Harbi FA, Näpänkangas R, Raustia A. PMMA denture base material enhancement: a review of fiber, filler, and nanofiller addition. Int J Nanomed. 2017; 12: 3801-3812.

PubMed: https://www.ncbi.nlm.nih.gov/pmc/articles/PMC5440038/

14. Elshereksi N, Ghazali M, Muchtar A, Azhari C. Perspectives for 
Titanium-Derived Fillers Usage on Denture Base Composite Construction: A Review Article. Adv Mater Sci Eng. 2014. 1-13.

15. Al-Harbi FA, Abdel-Halim MS, Gad MM, Fouda SM, Baba NZ, et al. Effect of Nanodiamond Addition on Flexural Strength, Impact Strength and Surface Roughness of PMMA Denture Base. J Prosthodont. 2019; 28: e417-e425.

PubMed: https://pubmed.ncbi.nlm.nih.gov/30353608/

16. Darwish G, Huang S, Knoernschild K, Sukotjo C, Campbell S, et al Improving Polymethyl Methacrylate Resin Using a Novel Titanium Dioxide Coating. J Prosthodont. 2019; 28: 1011-1017.

PubMed: https://pubmed.ncbi.nlm.nih.gov/30720223/

17. Kylián $O$, Shelemin $A$, Solař $P$, Pleskunov $P$, Nikitin $D$, et al. Magnetron Sputtering of Polymeric Targets: From Thin Films to Heterogeneous Metal/Plasma Polymer Nanoparticles. Materials (Basel). 2019; 12: 2366. PubMed: https://pubmed.ncbi.nlm.nih.gov/31349580/

18. Chodun R, Skowroński Ł, Okrasa S, Wicher B, Nowakowska-Langier K, et al. Optical TiO2 layers deposited on polymer substrates by the Gas Injection Magnetron Sputtering technique. Applied Surface Sci. 2019; 466: 12-18.

19. Pasha KA. Flexural Strength in Three Types of Denture Base Resins. Int J Res Health Allied Sci. 2018; 4: 29-32.

20. Nakano R, Ishiguro $H$, Yao $Y$, Kajioka J, Fujishima $A$, et al. Photocatalytic inactivation of influenza virus by Titanium dioxide thin film. Photochem Photobiol Sci. 2012; 11: 1293-1298. PubMed: https://pubmed.ncbi.nlm.nih.gov/22580561/

21. Prajwala N, Kumar CR, Sujesh M, Rao DC, Pavani L. Denture base reinforcing materials - A review. IP Ann Prosthodont Restor Dent 2020; 6: 52-59.

22. AbdulrazzaqNajiS, JafarzadehKashiT,BehroozibakhshM,HajizamaniH, Habibzadeh S. Recent Advances and Future Perspectives for Reinforcement of Polymethyl methacrylate Denture Base Materials: A Literature Review. J Dent Biomater. 2018; 5: 490-502.

23. Ozyildiz E, Guden M, Uzel A, Karaboz I, Akil O, et al. Antimicrobial Activity of TiO2-coated Orthodontic Ceramic Brackets against Streptococcus mutans and Candida albicans. Biotechnol Bioproc Engineer. 2010; 15: 680-685.

24. Cheng YY, Cheung WL, Chow TW. Strain analysis of maxillary complete denture with three-dimensional finite element method. J Prosthet Dent. 2010; 103: 309-318.

PubMed: https://pubmed.ncbi.nlm.nih.gov/20416415/
25. Morsy M, Al-Daous M. Gold Nanoparticles-PMMA Composite for denture base: Synthesis, Mechanical and Thermal Characteristics. AKU J Sci Eng. 2014; 14: 369-374.

26. Oyar P, Sana FA, Nasseri B, Durkan R. Effect of green Gold nanoparticles synthesized with plant on the flexural strength of heatpolymerized acrylic resin. Niger J Clin Pract. 2018; 21: 1291-295. PubMed: https://pubmed.ncbi.nlm.nih.gov/30297561/

27. Mehta G, Grover A, Nagda SJ. Comparison of flexural strength of two commercially available Heatpolymerized PMMA. Int J Appl Dent Sci. 2018; 4: 367-370.

28. Johnston EP, Nicholls JI, Smith DE. Flexure fatigue of 10 commonly used denture base resins. J Prosthet Dent. 1981; 46: 478-483. PubMed: https://pubmed.ncbi.nlm.nih.gov/6946217/

29. Hashem M, Al Rez MF, Fouad H, Elsarnagawy T, El-Sharawy M, et al. Influence of Titanium Oxide Nanoparticles on the Physical and Thermomechanical Behavior of PolyMethyl Methacrylate (PMMA): A Denture Base Resin. Science of Advanced Materials. 2017; 9: 938-944.

30. Sodagar A, Bahador A, Khalil S, Shahroudi AS, Kassaee MZ. The effect of $\mathrm{TiO} 2$ and $\mathrm{SiO} 2$ nanoparticles on flexural strength of Polymethyl methacrylate) acrylic resins. J Prosthodont Res. 2013; 57: 15-19. PubMed: https://pubmed.ncbi.nlm.nih.gov/23200530/

31. Wang W, Liao S, Zhu Y, Liu M, Zhao Q, et al. Recent Applications of Nanomaterials in Prosthodontics. J Nanomaterials. 2015; 1-11.

32. Karci M, Demir N, Yazman S. Evaluation of Flexural Strength of Different Denture Base Materials Reinforced with Different Nanoparticles. J Prosthodont. 2019; 28: 572-579.

PubMed: https://pubmed.ncbi.nlm.nih.gov/30298558 /

33. Chatterjee A. Properties improvement of PMMA using nano TiO2. J Appl Polym Sci. 2010; 118: 2890-897.

34. Konchada J, Karthigeyan S, Ali SA, R V, Amirisetty R, Dani A. Effect of simulated microwave disinfection on the mechanical properties of three differenttypesofdenturebaseresins.JClinDiagnRes.2013;7:3051-3053. PubMed: https://pubmed.ncbi.nlm.nih.gov/24551725/

35. Gad MM, Abualsaud R, Al-Thobity AM, Baba NZ, Al-Harbi FA. Influence of Addition of Different Nanoparticles on the Surface Properties of Polymethyl methacrylate Denture Base Material. J Prosthodont. 2020; 29: 422-428.

PubMed: https://pubmed.ncbi.nlm.nih.gov/32233047/

36. Akay C, Nur Avukat E. Effect Of Nanoparticle Addition on Polymethyl methacrylate Resins. Acta Sci Dent Sci. 2019; 3: 91-97. 